\title{
Coating of Solid Phase with Antigen, Antibody, or Nucleic Acid for in Vitro Diagnostics Device
}

National Cancer Institute

\section{Source}

National Cancer Institute. Coating of Solid Phase with Antigen, Antibody, or Nucleic Acid for in Vitro Diagnostics Device. NCI Thesaurus. Code C113044.

The act of immobilizing one or more detection agents to a solid-phase support for an in vitro diagnostic device. 